\title{
MEMBANDINGKAN TEGANGAN PERMUKAAN DENGAN TEGANGAN AIR MENGGUNAKAN ZAT PEWARNA MAKANANAN SEBAGAI ALAT PERAGA PEMBELAJARAN
}

\author{
Eka Yulisari Asmawati \\ Sekolah Menengah Atas Negeri 1 Metro \\ E- Mail: ekayulisariasmawati@gmail.com
}

\begin{abstract}
Have performed experiments to compare the surface tension of water by the surface tension of alcohol use food dye. The research method is to perform a simple test. With a drop of food dye into water will make the water molecules become larger and when alcohol was dropped into the solution there will be a tug between water and alcohol with water or with alcoholcalled cohesion. Tug between different molecules such as water to alcohol is called adhesion. Cohesion of water molecules is greater than the cohesion of the alcohol molecules. Cohesion of water is also greater than the adhesion between the two fluids. Competition between cohesion and adhesion molecules of water and alcohol lead to mutual attraction between water and alcohol resulting in vibrations when the fluid is met. The results obtained when this trial is water that has spilled food dye will move away from the alcohol and water colored parts that come into contact with alcohol will vibrate.
\end{abstract}

Keywords: surface tension, food dyes, alcohol, cohesion, adhesion

\section{PENDAHULUAN}

Hakikat pembelajaran IPA adalah proses dan produk. Oleh karena itu, pembelajaran IPA di sekolah tidak hanya mementingkan penguasaan fisika terhadap fakta konsep dan teori IPA (sebagai produk) tetapi yang lebih penting adalah siswa mengerti proses bagaimana fakta dan teori-teori tersebut ditemukan. Dengan kata lain siswa harus mendapat pengalaman langsung dan menemukan sendiri proses tersebut (Depdiknas, 2006).

Penggunaan alat peraga dan alat praktikum dalam pembelajaran dapat meningkatkan keterampilan berfikir kritis dan hasil belajar siswa. Oleh karena itu, dalam penelitian ini digunakan suatu alat peraga untuk meningkatkan minat dan motivasi siswa, serta penguasaan konsepnya. Slameto (2010:57) menjelaskan bahwa minat adalah kecenderungan yang tetap untuk memperhatikan dan mengenang beberapa kegiatan. Kegiatan yang diminati seseorang, diperhatikan terus menerus disertai dengan rasa senang.

Harapan agar proses pembelajaran mampu meberikan pengalaman kepada siswa, maka perlu adanya eksperimen dan demonstrasi atau peraga yang berlangsung dengan menyenangkan. Penggunaan alat peraga dan alat praktikum mempunyai beberapa manfaat yaitu untuk meletakkan dasardasar yang nyata dalam berfikir, mengurangi terjadinya verbalisme, memperbesar minat dan perhatian peserta didik untuk belajar, meletakkan dasar perkembangan belajar agar hasil belajar bertambah mantap, memberikan pengalaman yang nyata untuk dapat menumbuhkan kegiatan berusaha sendiri pada setiap peserta didik, menumbuhkan pemikiran yang 
teratur dan berkesinambungan, membantu tumbuhnya pemikiran dan berkembangnya kemampuan berbahasa, memberikan pengalaman yang tidak mudah diperoleh dengan cara lain serta membantu berkembangnya efisiensi dan pengalaman belajar yang lebih sempurna.

Salah satu materi yang dapat digunakan atau diangkat sebagai materi peraga adalah materi tentang tegangan permukaan.

Air adalah zat atau materi atau unsur yang penting bagi semua bentuk kehidupan yang diketahui sampai saat ini di bumi, tetapi tidak di planet lain. Air menutupi hampir $71 \%$ permukaan bumi. Terdapat 1,4 triliun kubik (330 juta milis) tersedia di bumi.

Air adalah salah satu sumber kekuatan dan energi yang ada di bumi ini. Air merupakan sebuah elemen dan partikel cair. Tanpa air, semua makhluk hidup tidak dapat bertahan hidup dan akan mati. Manfaat Air Dalam kehidupan contohnya adalah Air terjun. Air terjun mengandung tenaga gerak yang dapat dimanfaatkan oleh manusia, misalnya untuk pembangkit tenaga Listrik. Bendungan (dam) akan menahan aliran air dan membentuk danau (waduk). Air yang berada di waduk disalurkan lewat terowongan ke kincir air khusus (Turbin). Selanjutnya, turbin menggerakan dinamo (generator) yang menghasilkan aliran listrik sangat besar. Tenaga listrik tersebut dialirkan ke kota dan desa, misalnya untuk menggerakan mesin di pabrik serta penerangan di rumah, sekolah, dan pertokoan.
Alkohol (atau alkanol) adalah istilah yang umum untuk senyawa organik apa pun yang memiliki gugus hidroksil $(-\mathrm{OH})$ yang terikat pada atom karbon, yang ia sendiri terikat pada atom hidrogen dan/atau atom karbon lain. Alkohol sering dipakai untuk menyebut etanol, yang juga disebut grain alcohol; dan kadang untuk minuman yang mengandung alkohol. Hal ini disebabkan karena memang etanol yang digunakan sebagai bahan dasar pada minuman tersebut, bukan metanol, atau grup alkohol lainnya. Begitu juga dengan alkohol yang digunakan dalam dunia famasi. Alkohol yang dimaksudkan adalah etanol. Sebenarnya alkohol dalam ilmu kimia memiliki pengertian yang lebih luas lagi.

Pada umumnya, hampir semua materi fisika perlu diajarkan dengan terlebih dahulu menunjukkan gejala alam terjadi. Itu sesuai dengan sifat empiric dari fisika itu sendiri. Untuk menunjukkan gejala itu, baik gejala yang sesungguhnya ataupun analogi dari gejala yang sesungguhnya, diperlukan alat-alat dan bahan-bahan untuk melakukan percobaan.

Etanol, disebut juga etil alkohol, alkohol murni, alkohol absolut, atau alkohol saja, adalah sejenis cairan yang mudah menguap, mudah terbakar, tak berwarna, dan merupakan alkohol yang paling sering digunakan dalam kehidupan sehari-hari. Senyawa ini merupakan obat psikoaktif dan dapat ditemukan pada minuman beralkohol dan termometer modern. Etanol adalah salah satu obat rekreasi yang paling tua. Etanol termasuk ke dalam alkohol 
rantai tunggal, dengan rumus kimia $\mathrm{C} 2 \mathrm{H} 5 \mathrm{OH}$ dan rumus empiris $\mathrm{C}_{2} \mathrm{H}_{6} \mathrm{O}$. Ia merupakan isomer konstitusional dari dimetil eter.

\section{PROSEDUR PERCOBAAN}

Prosedur proses ini dilakukan dengan beberapa tahapan yaitu, persiapan alat-bahan, uji coba dan setelah itu melakukan pengamatan.

Alat dan bahan yang harus di persiapkan adalah sebagai berikut :
1. Air
2. Piring
3. Sendok

4. Alkohol

5. Pewarna makanan

Setelah alat dan bahan siap, maka mulai untuk menguji coba dengan langkah-langkah sebagai berikut:

1. Tuangkanlah sedikit air kedalam piring sehingga menutupi permukaan piring dengan lapisan yang setipis mungkin.

2. Teteskan 2 tetes pewarna makanan dan aduk

3. Masukkan 1 sendok makan alkohol ke bagian tengah air yang berwarna

4. Lalu amati getaran yang terjadi.
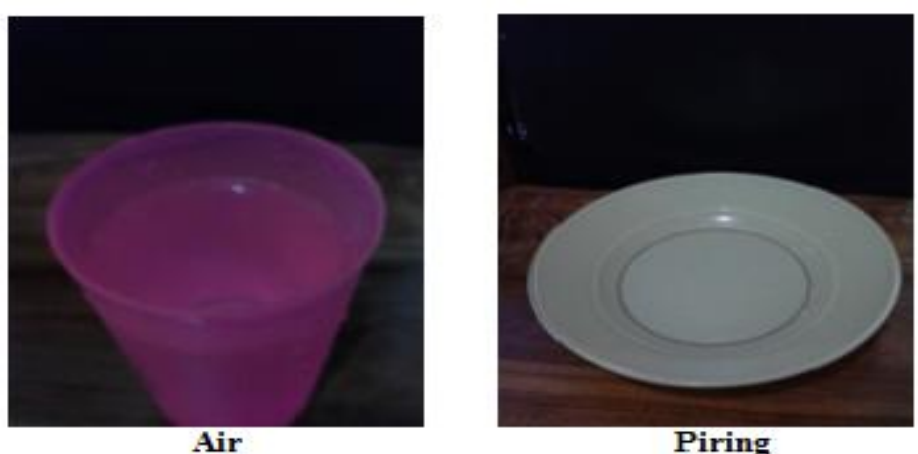

Piring

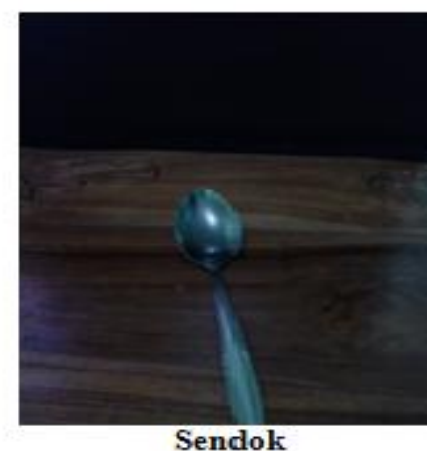

Sendok

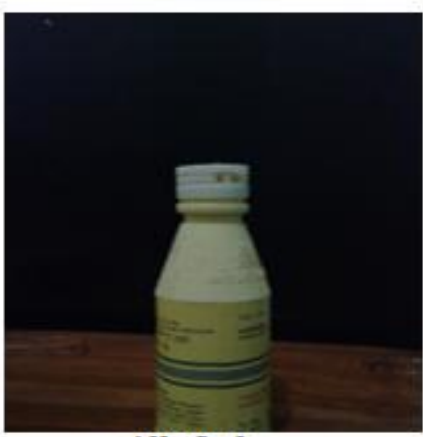

Alkohol

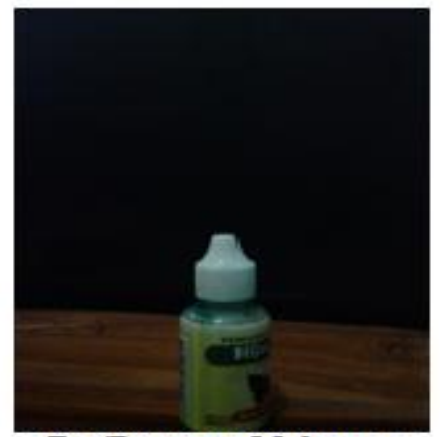

Zat Pewarna Makanan

Gambar 1. Alat dan Bahan Percobaan 

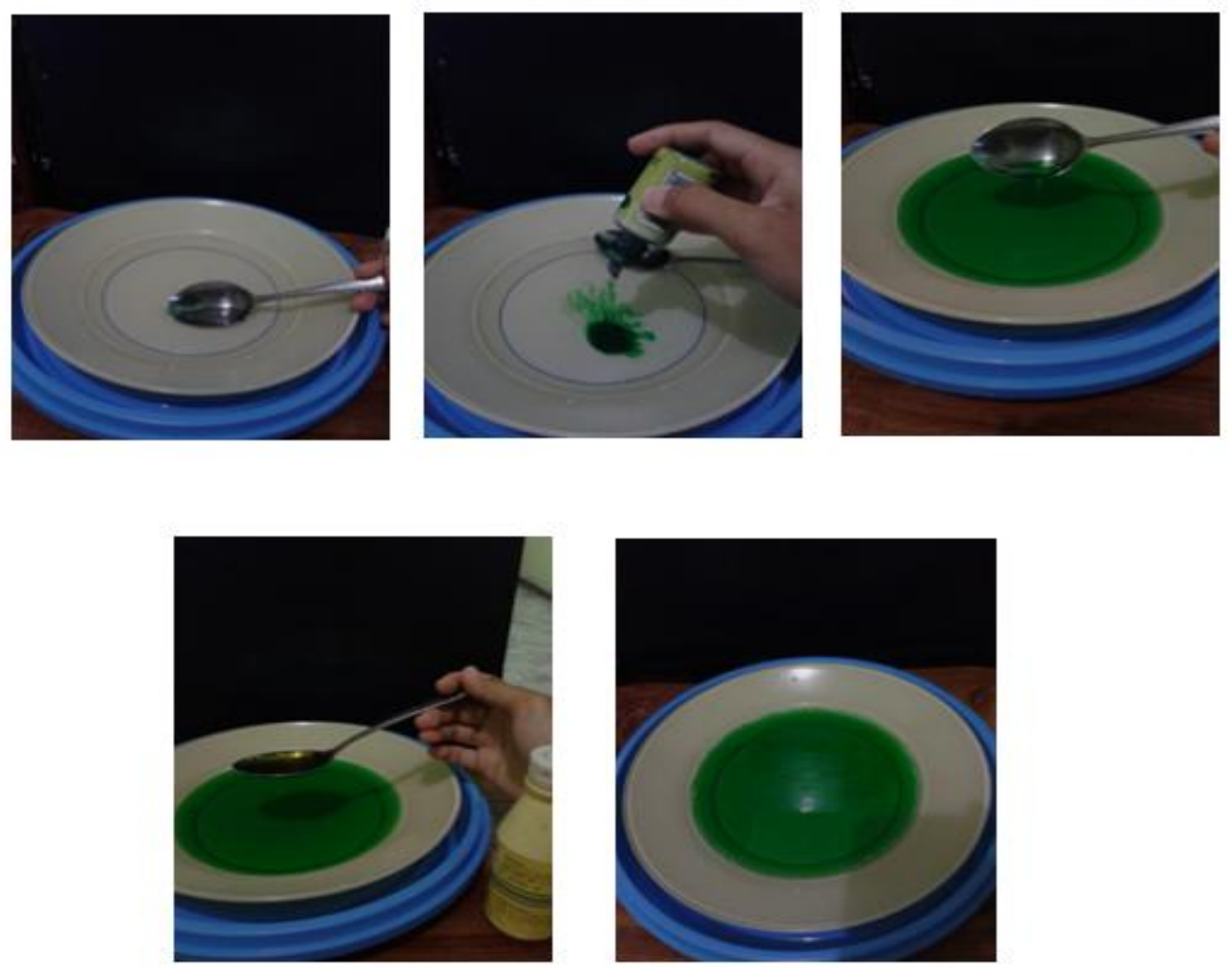

Gambar 2. Langkah-langkah Percobaan

\section{HASIL DAN PEMBAHASAN}

Air yang telah diletakkan di piring semula berwarna bening tetapi setelah

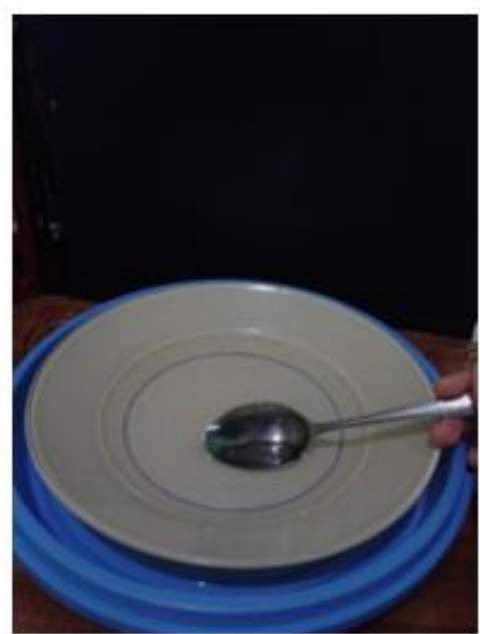

ditetesi oleh zat pewarna makanan maka warnanya akan berubah seperti Gambar $3 .:$

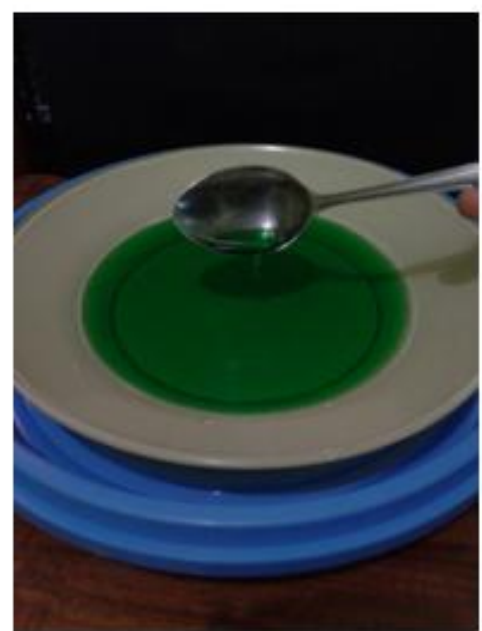

Gambar 3. Tahapan Percobaan 


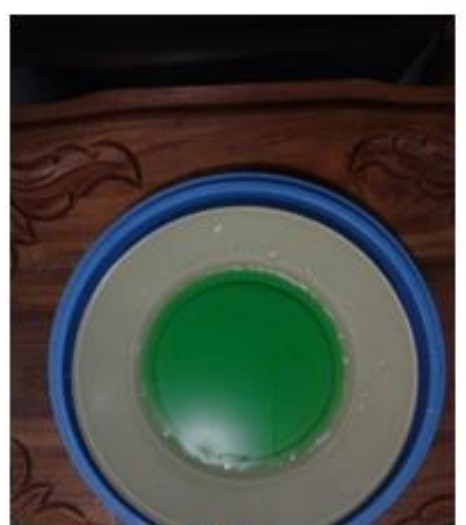

Air Berwarna

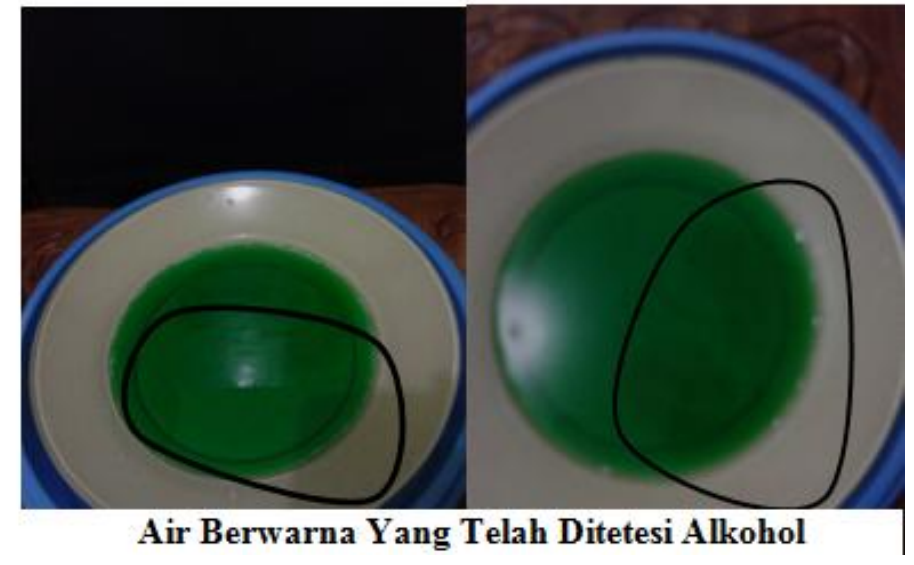

Gambar 4. Hasil Percobaan
Lalu ketika sudah tercampur, tuangkan alkohol sebanyak 1 sendok makan kedalam air yang berwarna tersebut.

Pada percobaan yang telah dilakukan diperoleh hasil pengujian data yaitu ketika alkohol yang dimasukkan kedalam air berwarna membuat air berwarna akan bergerak menjauh dari alkohol dan bagian dari pinggir air yang bersentuhan akan bergetar (nampak pada gambar pemisahan air dan alkohol).

Pemisahan air ini terjadi karenaadanya kohesi dan adhesi pada air dan alkohol. Kohesi adalah gaya tarik menarik anatara molekul yang sama, seperti air dengan air atau alkohol dengan alkohol. Kohesi dipengaruhi oleh kerapatan dan jarak antarpartikel dalam zat. Gaya kohesi mengakibatkan dua zat bila dicampurkan tidak akan saling melekat. Sedangkan adhesi adalah gaya tarik menarik antara molekul yang tak sejenis seperti air dengan alkohol. Gaya adhesi akan mengakibatkan dua zat akan saling melekat bila dicampurkan. Kohesi molekul-molekul air lebih besar dibandingkan daya kohesi alkohol. Kohesi air juga lebih besar dibandingkan daya adhesi antara air dan alkohol. Sehingga air tidak menyatu dengan alkohol. Kompetisi antara daya kohesi dan adhesi pada molekul-molekul air dan alkohol menyebabkan saling tarik menarik antara air dan alkohol sehingga terjadi getaran ketika kedua cairan ini bertemu.

\section{KESIMPULAN}

Berdasarkan analisis data dan
pembahasan dapat diperoleh
kesimpulan bahwa:

1. Zat pewarna mengubah molekul-molekul air yang seharusnya bisa menyatu sempurna dengan alkohol dengan adanya daya kohesi dan adhesi yang sama.

2. Air yang berwarna itu memiliki daya kohesi yang lebih besar dibandingkan dengan daya adhesi antara air dan alkohol.

3. Ketika terjadi kompetisi antara daya kohesi dan adhesi pada air 
bewarna dan alkohol maka akan terjadi getaran.

\section{DAFTAR PUSTAKA}

1. VanCleave, Janice.2003.204

Percobaan-Percobaan Yang

Menakjubkan.Pakar Karya:

Bandung

2. Sainschem.2012.Makalah

Kimia Alkohol [Online]

tersedia:

http://sainschem.blogspot.com/

diakses pada 13 Juni 2014

pukul 21.30 WIB

3. Cahyanintyas,

Andini.2010.Tegangan

Permukaan [Online] tersedia:

http://andinicahyanintyas-

maniac.blogspot.com/ diakses

pada 13 Juni 2014 pukul 21.30

WIB

4. Secretto-12uP.2011. Pengertian dan Manfaat Air dalam

Kehidupan [Online] tersedia: http://secretto12up.blogspot.co $\mathrm{m} / 2011 / 12 /$ pengertian-danmanfaat-air-dalam.html diakses pada 13 Juni 2014 pukul 21.40 WIB

Herdianto, Wawan.2010.Kohesi dan Adhesi [Online] tersedia:

http://wawanfisika.wordpress.com/201 0/09/30/kohesi-dan-adhesi/ diakses pada 13 Juni 2014 pukul 22.12 WIB 